16. VAN DER Hokve, J.: "Scleromalacia Perforans," Arch. Ophth., 1934, 11, 111.118.

17. Imrie, A. H., and ATtKrenherad, A. C.: "Amyloidosis Complicating Still's Disease," Lancet, 1939, 2, 421-422.

18. LUX, LYDIA: "Subcutaneous Nodules Induced by Injection of Streptococcus Viridans," Arch. of Path., 1934, 17, 652-662.

19. MASTE, A. M., and Jorre, H.: "Rheumatoid Arthritis and Acute Rheumatic Fever," J.A.M.A., 1932, 98, 881-882.

20. McCrae, Thomas: "Arthritis Deformans: 110 Cases from Johns Hopkins Hospital," J.A.M.A., 1904, 42, 1; 94; 161.

21. Mmufr, J. L.: "A Critical Review of Literature of Chronic Rheumatism," Arch. Int. Med., 1936, 57, 213-234.

22. Nichols, E. H., and Richardson, F. S.: "Arthritis Deformans," J. of Med. Research, 1909, 21, 149-221.

23. Rigleer, Leo, and WeTherby, M.: "Roentgen Findings in Chronic Polyarticular Arthritis," Am. J. Roent. and Radium Therapy, 1933, 29:6, 766-773.

24. ShapIRO, M. J.: “Non-tuberculous Arthritis," J.A.M.A., 1932, 98, 19651968.

25. SnvGer, H. A., and Levy, H. A.: “ Relationship of Felty's Allied Syndromes to Sepsis Lenta," Arch. Int. Med., 1936, 57, 576-600.

26. Strennberg, C. L.: " Pathology of Atrophic Arthritis," J. of Lab. and Clinic. Med., 1942, 27, 435-442.

27. STIIL, G. F.: "Chronic Joint Disease in Children," Med.-Chir. Transactions, London, 1896, 80, 47.

28. Verhoetr, F. H., and KnNG, Merrill J.: "Scleromalacia Perforans," Arch. Ophth., 1938, 20, 1013.

29. WhTHERBY, M.: "Incidence of Subcutaneous Nodules in Arthritis." (Personal Communication.)

\title{
BLOOD CULTURES IN RHEUMATOID ARTHRITIS
}

\section{(Historical and Personal Observations)}

\section{BY THOMAS N. FRASER}

THE problem of microbic infection in relation to the ætiology of rheumatoid arthritis has led to much discussion and experiment. Evidence of infection, particularly by streptococci, has been sought for both directly by blood cultures and indirectly by the study of immunity reactions of different kinds. The result of all this body of work remains entirely inconclusive, and it may seem redundant to burden the literature with further negative and inconclusive results.

While carrying out intensive observations on a group of cases of rheumatoid arthritis, however, a good opportunity was presented of repeating previous observations on blood cultures on this disease, and these have been contrasted in Table I. with the results of the majority of previous workers in this field.

The observations on blood cultures which have undoubtedly 
attracted the greatest attention in recent years, both in Britain and America, were those of Cecil, Nicholls and Stainsby (1929), using a complicated technique in which the possibilities of contamination are clearly abundant. Recently (1940), since the present bacteriological investigations were completed, Cecil has retracted his previous results admitting the probability of contamination.

The present work was begun in 1937, before Cecil had withdrawn from his earlier position, and to constitute a direct control the same technique as that used by Cecil was carried out in its entirety. This was essentially a modification of Clawson's method (1925), and, as the table shows, this technique, or modifications of it, has been used by many other workers.

\section{Historical}

Bannatyne, Wohlman and Blaxall (1896) were the first to report the recovery of organisms in the blood of patients with rheumatoid arthritis, and were able to demonstrate the presence of a minute bacillus with marked polar staining. Others continued this work, but the percentage of positive cultures has been variable, and the organisms isolated of different types.

Cecil, Nicholls and Stainsby (1929) obtained positive blood cultures in 69 per cent. of seventy-eight patients, using their special technique referred to below. The great majority of organisms recovered were attenuated hæmolytic streptococci and were named "typical strains" by the authors. Others have repeated this work, but the majority have failed to confirm the high incidence of positive cultures obtained by Cecil. Support was received from Gray and Gowen (1931), Ashworth (1932), and Strauss (1932), and condemnation from Bernhardt and Hench (1930), Dawson, Olmstead and Boots (1932), and Wainwright (1934).

\section{Technique of Blood Culture}

The technique employed by Cecil (1929) was followed in the strictest detail, and may be summarised as follows:

Blood is withdrawn from the antecubital vein, and 10 c.c. are placed in each of two sterile centrifuge tubes, thus providing duplicate samples for the culture. After centrifuging, the supernatant serum is removed by a sterile pipette. Each tube containing blood clot is now treated in the following manner: The clot is broken up by means of a piece of hollow glass tubing, and the fragments of clot are drawn up in the same glass tube and transferred to a 3-ounce culture flask containing 50 c.c. of beef-heart infusion broth with a $\mathrm{pH}$ of $7.6(0.5$ per cent. sodium chloride, 1 per cent. peptone). The flask is then incubated at $37^{\circ} \mathrm{C}$. and left unopened for five days.

At the end of this time subcultures are made. A tube containing 
8 c.c. of a 1.5 per cent. beef-heart infusion agar is placed in a waterbath and heated until the agar is completely melted. The agar is then partially cooled; 0.5 c.c. of whole rabbit blood and 0.1 c.c. of broth from the primary culture is added to it and the contents poured into a petri dish. This subculture in a solid medium is allowed to incubate for twenty-four to forty-eight hours, and is then examined. Similar subcultures are made every three to five days until the primary culture has been in incubation for thirty days. If at the end of this time the subcultures are still sterile, the sediment in the primary culture flask is removed with a glass tube and centrifuged. Part of the sediment is examined by making stained smears, while the remainder is incubated both in fresh blood broth and on blood-agar plates. If these final subcultures show no growth, the blood culture is considered to have been sterile.

\section{Personal Observations}

1. Rheumatoid Arthritis.-For the investigation blood cultures were made from sixty-one patients. Fifty-one of these were women and ten were men. Their ages varied from 15 to 93 years; thirty-two were under 50 years of age and twenty-nine were 50 or over. In seventeen of the patients the disease had been present for less than a year; in twenty, from one to five years; in seven, from six to ten years; and in fourteen, for more than ten years. In three, all of whom were over 75 years of age, the duration was not obtained, but each stated that she had had the condition for many years.

All patients presented the clinical syndrome of pain, stiffness and swelling of several joints. In all but three the joints of the fingers were involved and showed the characteristic fusiform swelling associated with the disease. In two of the others the knees were affected, and in the third the elbows and shoulders. In addition to pain, stiffness, and swelling of the joints the majority showed some degree of deformity or ankylosis. As in Cecil's series, the patients were free from fever in all but two instances at the time the cultures were made. Forty-five patients were confined to bed and sixteen were ambulatory. In eleven cases the blood was taken from the patient while in the actual process of undergoing some form of physiotherapy, such as massage or passive movements, to test whether such treatment might tend to liberate organisms into the blood stream and increase the chance of obtaining positive cultures.

Streptococci were never isolated. No organisms of any kind were recovered from the blood of fifty-eight of the sixty-one patients after thirty days incubation. In the remaining three, diphtheroid bacilli were isolated. In none of the eleven patients from whom the blood was removed during physical treatment (massage or passive movements) was a positive culture obtained. 
THE RHEUMATIC DISEASES

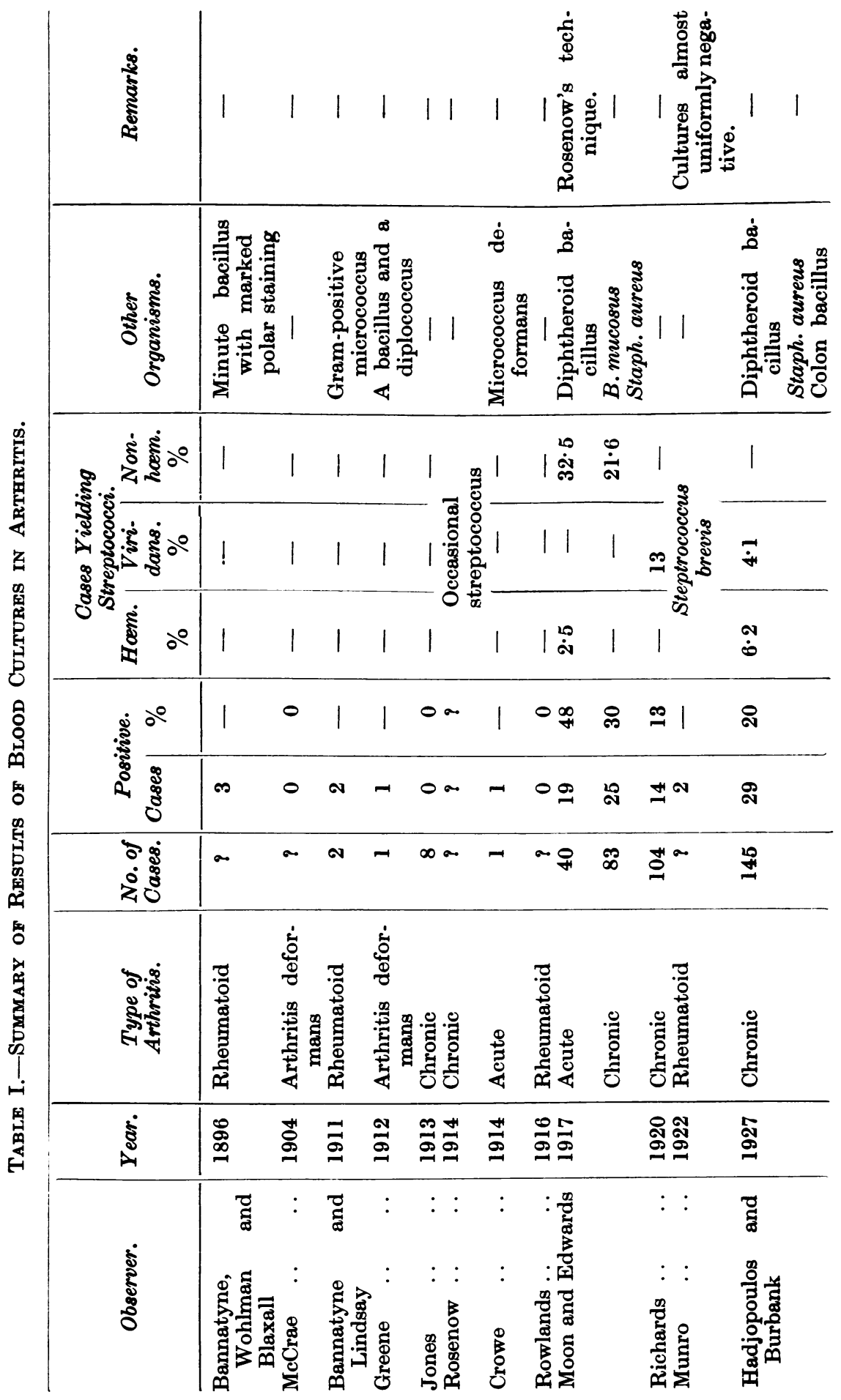


BLOOD CULTURES IN RHEUMATOID ARTHRITIS 185

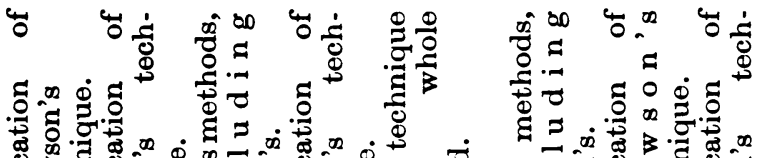

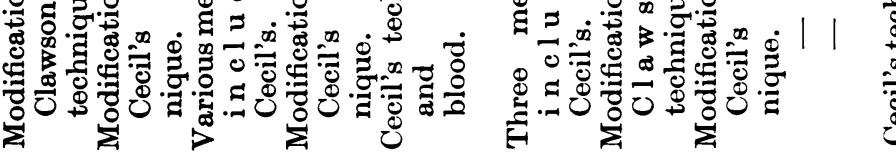

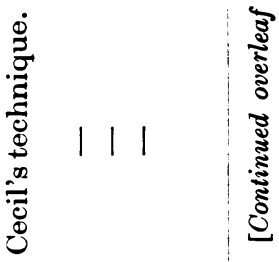

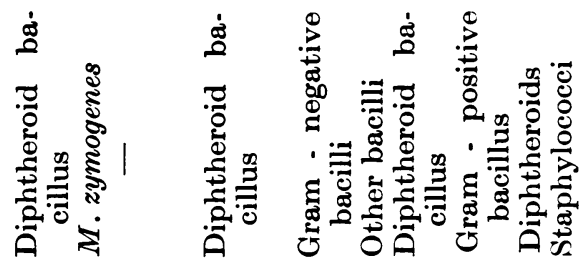

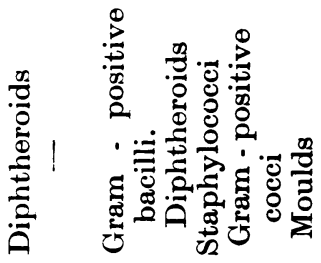

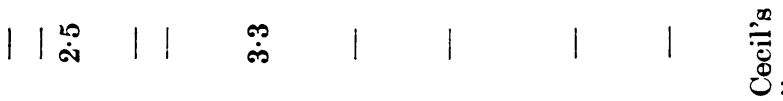

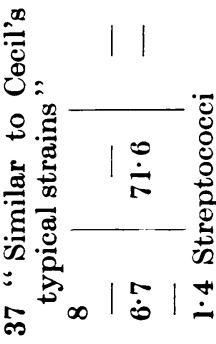

离

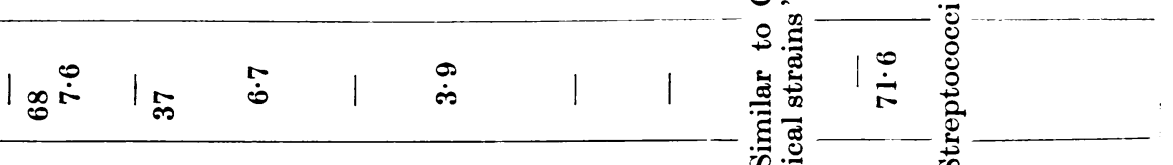

要

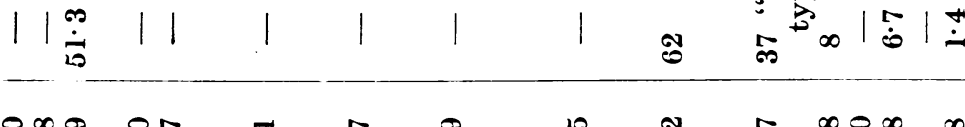

잉 묭

○上范 ON

\begin{tabular}{|c|c|c|c|c|c|c|c|c|c|}
\hline - 노요 & 보요 & $\infty$ & న్ల & $\stackrel{\sim}{*}$ & สิ & $\stackrel{\Delta}{\stackrel{G}{g}}$ & $\stackrel{\varrho}{\ddagger}$ & ボ & $\begin{array}{l}\text { ثั } \\
+\end{array}$ \\
\hline
\end{tabular}

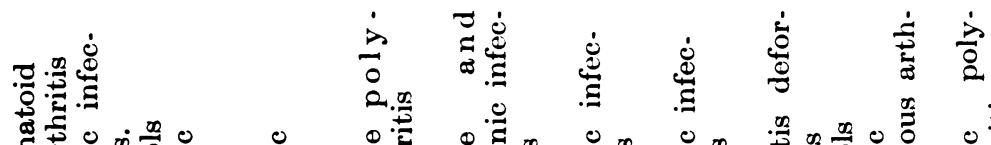

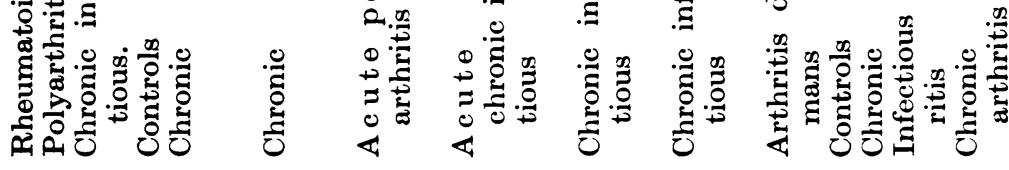

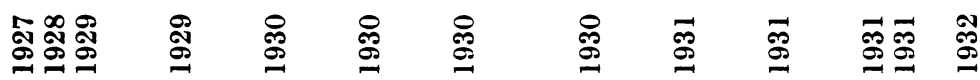

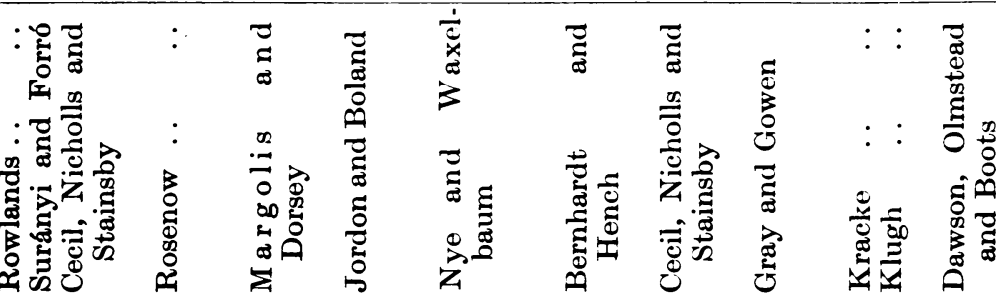


186

THE RHEUMATIC DISEASES

\begin{tabular}{|c|c|c|c|c|c|c|c|c|c|}
\hline हूँ & 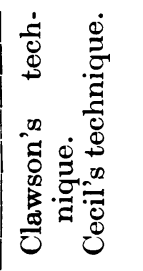 & 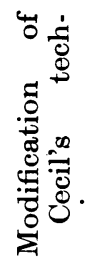 & 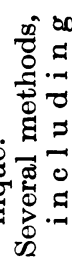 & & 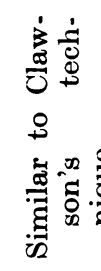 & 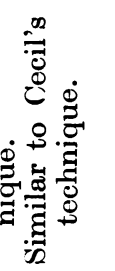 & 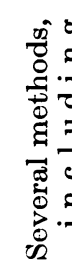 & 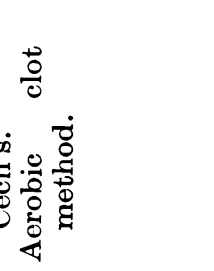 & 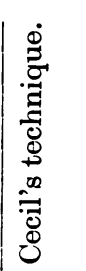 \\
\hline 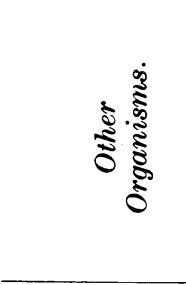 & 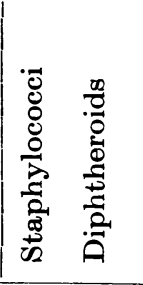 & 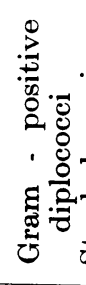 & 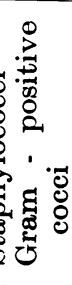 & 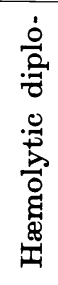 & 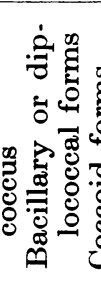 & 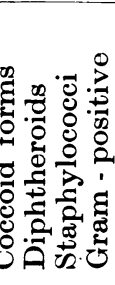 & 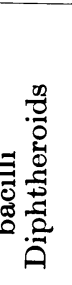 & 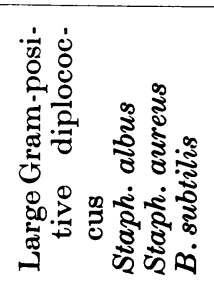 & 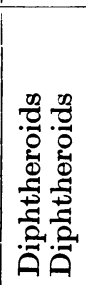 \\
\hline 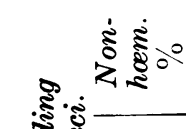 & & $\begin{array}{l}\hat{C}_{0}^{\infty} \\
\underbrace{\infty}_{0}= \\
0\end{array}$ & $\dot{\dot{H}}$ & 1 & 11 & 1 & 10 & 营 & 11 \\
\hline 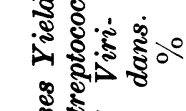 & 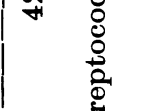 & 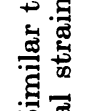 & 1 & 1 & 11 & - & 0 & $\dot{\dot{\Xi}}$ & 10 \\
\hline $0^{82}{ }^{8}{ }^{\circ}$ & $\stackrel{\sim}{-} N \dot{0}$ & 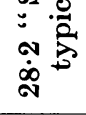 & 1 & 오 & 11 & 1 & $\infty$ & $\frac{2}{4}$ & 11 \\
\hline : & 迨 N 20 & P & $\infty$ & สิ & $\Sigma^{\circ}$ & $\dddot{\rightarrow}$ & 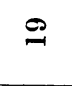 & สิ & $20 \infty$ \\
\hline $\begin{array}{r}\infty \\
2.8 \\
8 \\
8 \\
0\end{array}$ & జ్లే ニ & 8 & $H$ & N & $\mathbf{N}^{\circ}$ & $\cong$ & $r$ & $\stackrel{\boldsymbol{\sim}}{\sim}$ & o \\
\hline 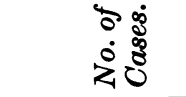 & 16 & $\stackrel{\infty}{\mathscr{m}}$ & $\stackrel{\infty}{+}$ & 오 & దొ & $\bar{\sigma}$ & $\infty 0$ & $\begin{array}{l}\overrightarrow{0} \\
+\end{array}$ & $\ddot{60}$ \\
\hline 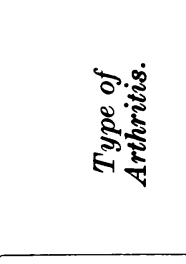 & 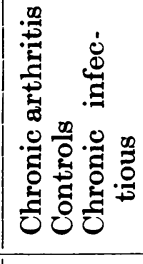 & 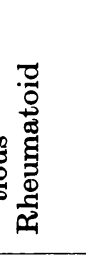 & 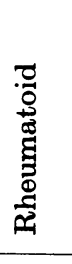 & 苫 & 象哭 & 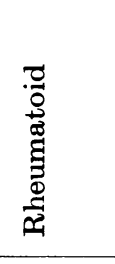 & 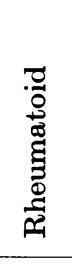 & 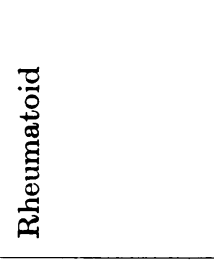 & 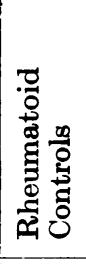 \\
\hline$\stackrel{\Xi}{ذ}$ & Æֶ̃ & 茑 & ્ֻఞ & 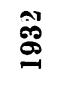 & 局 & 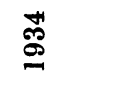 & ஜ̊̊口 & 용 & $\stackrel{\infty}{\mathscr{g}}$ \\
\hline 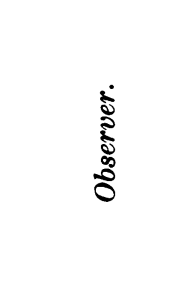 & 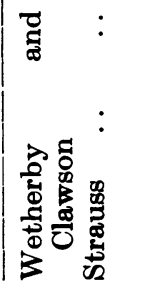 & $\begin{array}{c}: \\
: \\
: \\
\text { : } \\
\text { : } \\
\text { 要 }\end{array}$ & 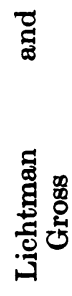 & 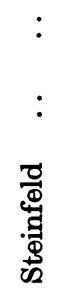 & 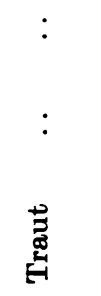 & 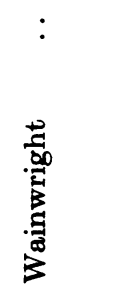 & 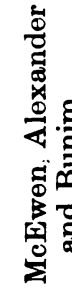 & 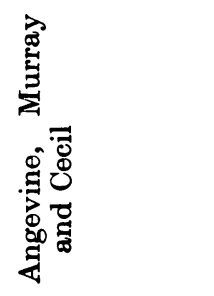 & 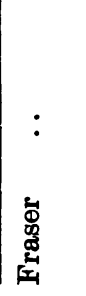 \\
\hline
\end{tabular}


2. Controls.-Blood cultures were made by Cecil's technique in sixty-one control patients. A large proportion of these were suffering from diseases due to chronic bacterial infection-e.g., chronic cholecystitis, chronic osteomyelitis, etc. A complete list of the series is given in Table II.

Following Okell and Elliott (1935), blood cultures were also taken after single or multiple dental extractions from twenty patients with apical infection or pyorrhœa alveolaris who were otherwise healthy, the blood being withdrawn within ten minutes of the dental operation. These workers found that a transient bacteriæmia developed in 61 per cent. of patients after dental extractions, due to the trauma. In the majority of these the organism was a streptococcus of the viridans type. Of more importance was the fact that in 11 per cent. of patients with septic mouths a streptococcal bacteriæmia was found irrespective

$$
\text { Table II.-Controls . }
$$

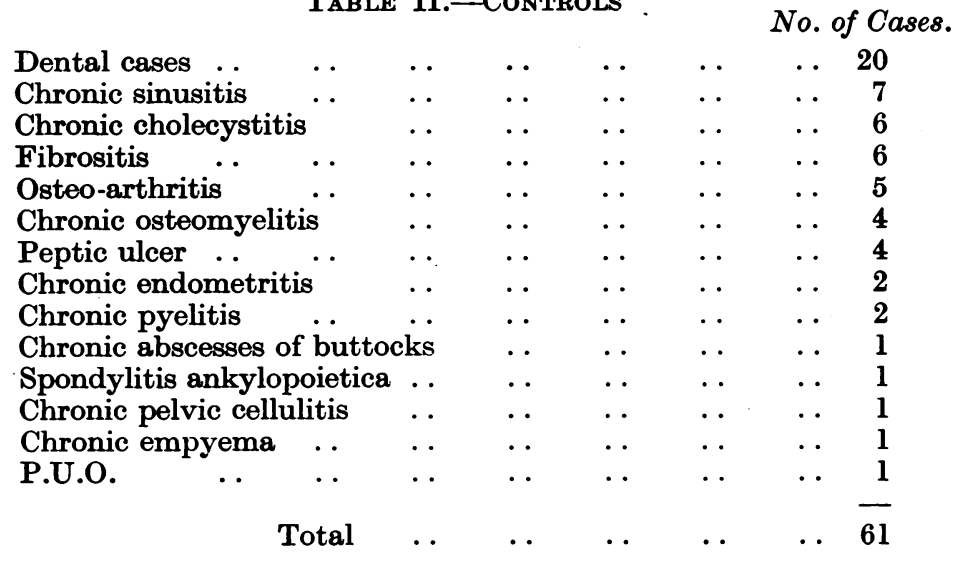

of any operative interference. It was suggested that in these patients the brushing of the teeth or the act of chewing might act as a trauma and cause a "leak" of relatively non-pathogenic organisms into the general circulation, followed by their rapid removal by the phagocytic action of the body.

Organisms were recovered from the blood of five of the sixty-one controls during thirty days incubation. In three of these the Streptococcus viridans was isolated and in two a diphtheroid bacillus. The former was obtained, after dental extraction for apical abscess, from the blood of three otherwise healthy patients, and the latter from patients with osteo-arthritis and fibrositis respectively. 


\section{Discussion}

The results of studies on blood cultures in patients with rheumatoid arthritis have been tabulated. From this sufficiently accurate data are available for a short analysis of the findings to be given. Including my own figures, details are given of blood cultures on 1,785 samples of blood taken from 1,619 patients. Of these, 1,159 (65 per cent.) were found to be sterile, and from the remaining 626 (35 per cent.) a variety of organisms was recovered. In 418 instances ( 23 per cent.) the blood yielded a streptococcus, and in the remaining 208 (12 per cent.) nonstreptococcal organisms were found, the most frequent of which were the diphtheroid bacillus and Staphylococcus albus.

From the table it will be noticed that the percentage of positive cultures obtained by various investigators varies considerably. Moreover, even among those who have obtained positive results there is a marked discrepancy in the type of organism recovered. I cannot claim that my findings in any way lessen this confusion.

Why should there be this disparity in the results obtained by various investigators? There are some (Nye and Waxelbaum, 1930; Wainwright, 1934) who view all positive results with suspicion and consider that the organisms recovered, including the streptococci, are contaminants. The possibilities of contamination in Cecil's technique are obviously numerous, and as Dawson, Olmstead and Boots (1932) pointed out, each subculture is subjected on an average to eighteen manipulations.

On the other hand, there are those who attach significance, not only to the streptococci, but to the diphtheroid bacilli and staphylococci which they recovered from the blood. Klugh (1931), Kracke (1931), and Strauss (1932) were all of the opinion that the diphtheroid bacillus was an involution form of the streptococcus. Callow (1933), in her work on rheumatic fever, noted that 51 per cent. of the organisms isolated from the blood were pleomorphic bacilli.

Many of the positive results obtained are rendered invalid by the absence of control cultures. Lichtman and Gross (1932) stressed the necessity of providing adequate controls and included a large number in their work. In my series blood cultures were made from sixty-one controls. These included several diseases due to chronic bacterial infection, such as chronic cholecystitis and chronic osteomyelitis. In none of these was a positive blood culture obtained.

Gray (1940) sums up the position fairly by saying that the presence of bacteria in the blood stream does not prove the microbic æatiology of rheumatoid arthritis, nor does the absence of bacteria disprove it. 


\section{SUMMARY}

1. Blood cultures were made from sixty-one patients suffering from rheumatoid arthritis. The method employed was that described in 1929 by Cecil and his co-workers. Streptococci were not recovered from any of the cultures; diphtheroid bacilli were isolated from three.

2. Blood cultures from sixty-one control patients, of whom over a third were suffering from diseases due to chronic bacterial infectione.g., chronic cholecystitis, chronic osteomyelitis, etc.-Streptococcus viridans was recovered from the blood of three patients after dental extraction for apical abscess, and a diphtheroid bacillus from a patient with osteo-arthritis and fibrositis respectively; fifty-six cultures were sterile.

3. A brief historical survey of blood culture studies in rheumatoid arthritis has been made and tabulated. Organisms have been recovered in 35 per cent. of cases, and of these 23 per cent. yielded streptococci of various types.

4. The significance of the results of blood culture has been discussed.

5. It is not justifiable to conclude from blood culture findings that rheumatoid arthritis is a disease of infective origin.

6. It is suggested, following Okell and Elliott, that bacteriæmia, due to trauma or treatment-e.g., massage-may occur and give rise to a positive blood culture; but the organisms reaching the blood may, or may quite well not, be ætiologically associated with rheumatoid arthritis.

Part of this work was undertaken while working for the Empire Rheumatism Council.

I wish to thank my colleagues at the Western Infirmary, Glasigow, for their kind co-operation.

\section{REFERENCES}

Asqevine, D. M., Rothbard, S., and Cecin, R. L. (1940): Proc. Amer. Rheumatism Ass., J. Amer. Med. A88., 115, 2111.

Ashworth, O. O . (1932): Virg. Med. Month., 59, 452.

BANNATYNE, G. A., and LINDSAY, J. (1911): Brit. Med. J., 1, 192.

Bannatyne, G. A., Wohlman, A. S., and Blaxall, F. R. (1896): Lancet, 1, 1120.

Bernhardt, H., and Hench, P. S. (1931): J. Infect. Dis., 49, 489.

Callow, B. R. (1933): J. Infect. Dis., 52, 279.

CrCII, R. L. (1933) : J. Amer. Med. Ass., 100, 1220.

Crell, R. L. (1940): Proc. Amer. Rheumatism Ass., J. Amer. Med. Ass., 115, 211.

CreIr, R. L., Nicholus, E. E., and Stannsby, W. J. (1929): Arch. Intern. Med., 43, 571.

Ceril, R. L., Nicholls, E. E., and Stannsby, W. J. (1931): Amer. J. Med. Sci., 181, 12. 
Clawson, B. J. (1925): J. Infect. Dis., 36, 444.

Crowe, H. W. (1930): J. Lab. Clin. Med., 15, 1072.

Dawson, M. H., Olmstead, M., and Boots, R. H. (1932): Arch. Intern. Med., 49, 173.

Gray, J. W. (1940): Proc. Amer. Rheumatism Ass., J. Amer. Med. Ass., 115, 2111.

Gray, J. W., and Gowen, C. H. (1931): Amer. J. Med. Sci., 182, 682.

Greene, H. M. (1912): New York Med.J., 2, 421.

Hadjopoulos, L. G., and Burbank, R. (1927): J. Bone and Joint Surg., 25, 278.

Jones, D. W. C. (1913): Brit. Med. J., 1, 1047.

Jordon, E. P., and Boland, J. P. (1930): J. Infect. Dis., 46, 148.

KLUGH, G. F. (1931): South. Med. J., 24, 706.

Kracke, R. R. (1931): Abstract, South. Med. J., 24, 708.

Lichtman, S. S., and Gross, L. (1932): Arch. Intern. Med., 49, 1078.

McCrae, T. (1904): J. Amer. Med. Ass., 42, 1.

McEwen, C., Alexander, R. C., and Bunim, J. J. (1936): J. Lab. Clin. Med., $21,453$.

Margolis, H. M., and Dorsey, A. H. E. (1930): J. Infect. Dis., 46, 442.

Moon, V. H., and Edwards, S. R. (1917): J. Infect. Dis., 21, 154.

MunRo, J. M. H. (1922): Lancet, 1, 938.

Nye, R. N., and Waxelbaum, E. A. (1930): J. Exp. Med., 52, 885.

OKell, C. C., and ElliotT, S. D. (1935): Lancet, $2,869$.

Richards, J. H. (1920): J. Bact., 5, 511.

Rosenow, E. C. (1914): J. Amer. Med. Ass., 63, 903.

Rosenow, E. C., quoted by Margolis and Dorsey (1930): J. Infect. Dis., 46. 442.

Rowlands, M. J. (1916): Lancet, 1, 133

Rowlands, M. J. (1927): Proc. R. Soc. Med., 20, 1711.

Steinfeld, F. (1932): (orig.) Zbl. Bakt., 123, 414.

Strauss, A. (1932): Virg. Med. Month., 58, 801.

Surányi, L., and Forr 6, E. (1928): Klin. Wschr., 7, 453.

Traut, E. F. (1933): J. Infect. Dis., 52230.

W ainwright, C. W. (1934): J. Amer. Med. Ass., 103, 1357.

Wetherby, M., and Clawson, B. J. (1932): Arch. Intern. Med., 49, 303.

\section{CORRESPONDENCE}

SIR,-The following are a few points which occur to me on reading Dr. Hughes' paper on Resistance in Rheumatism.

The basis of the whole paper seems to be invalidated by a confusion between hypersensitivity and resistance, as is shown by the example quoted of Koch's phenomenon and the tuberculin test, both of which are the result of hypersensitivity or allergy, and not necessarily connected with the degree of resistance. It is now established that hypersensitivity can occur independently of high resistance and vice versa, though admittedly they are often coincidences. Therefore, if the analogy between the effect of measles, pregnancy, etc., on the tuberculin 